\title{
A REVIEW ON AUTOMATION OF INDUSTRIES
}

\author{
Shubham Singh \\ Student, Department of Electrical Engineering \\ Bharati Vidyapeeth Deemed University \\ College of Engineering, PUNE, INDIA
}

\author{
Swapnil Namekar \\ Asst. Professor, Department of Electrical Engineering \\ Bharati Vidyapeeth Deemed University \\ College of Engineering, PUNE, INDIA
}

\begin{abstract}
Automation is the process by which the work is done much faster, hassle free, performed more accurately and precisely by reducing manpower and the number of people required. With the help of these automated machines critical jobs which human can't do, can be done very easily and conveniently. The basic necessity of "why automation?" as well as the devices or software which are used for automating the industry is also discussed. Here in this paper we have discussed about PLC, one of the digital computers used for the purpose of automation.
\end{abstract}

Keywords- Automation, Precise, Manpower, Critical, Conveniently, Robots, Software.

\section{INTRODUCTION}

With the recent advancement in the technology and the invention of computer the industries are turning towards the automation. Automation is the process by which the job is completed by using computer software or robots with higher degree of accuracy and precision. Automation of industries helps them to produce more goods with improved quality and accuracy in a predetermined time period. Automation also reduces labor cost.

Automation of industries are achieved by using various communication devices such as Programmable Logic Controller (PLCs) and Programmable Automation Controller (PACs) which are used to control the industrial machines and instruct machines how they had to do the job [1]

Since, automation reduces the involvement of human and thus reduces the chances of human error.

WHY AUTOMATION? - Let us consider an example. Suppose that one has a business of selling pancakes, initially a low budget business. Therefore, he may have 2 or 3 co-workers who will help him to prepare pancakes according to the recipe. But as soon as the business grows and the number of customers increases rapidly the manufacturing process must be made faster and more output is required with the same quality of product as [3] before. If the number of workers is increased then it may be possible that one of the co-workers may add any of the ingredient in excess or may do any other mistake which will reduce the quality of that batch of pancakes. This will result in a huge loss to the business, if the mistake is done frequently.

To overcome such problem of losses in business one needs to hire an engineering firm which will turn the process of manufacturing [5] into automatic manner. The automatic machines will perform the manufacturing job much faster, hassle free and more accurately by maintaining the quality of the product. With the help of such automatic machines the business will be more profitable and will [2] reduce the requirement of manpower. This is the root cause of why industrial automation is done. Many industries like steel manufacturing, textiles, oil and refinery etc. are nowadays automated. The following graph will suggest that why automation is better than manual method.

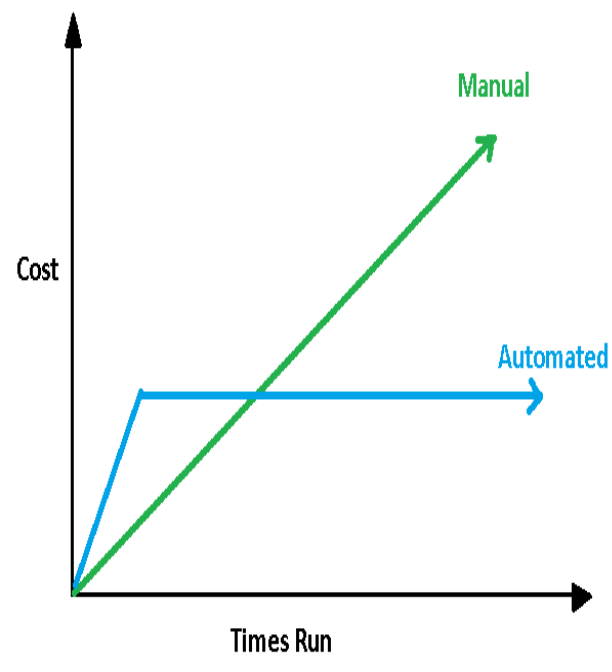

Graph to show the benefits of automation over manual method 


\section{PLC (Programmable Logic Controller) -} Automation of industries are done using a special purpose computer with no display, no keyboard, but then also it is a computer placed in a control panel which is again placed on the factory floor. Initially, relays were used for this purpose but because of their complicated connection, difficulties while troubleshooting and higher power consumption [6] they are replaced by PLC's. Programmable logic controller or (PLC) is a digital computer which is used to automate electromechanical processes such as controlling of industrial machinery etc.

PLC's are different from other computers in a manner that they can be used in harsh conditions such as in dust, moisture, heat and cold in an effective way.

PLC consist of a CPU module and Input/ Output (I/O) devices. Sometimes I/O is a part of CPU while other time not. It may be possible that the $\mathrm{CPU}$ and $\mathrm{I} / \mathrm{O}$ module are far apart but are connected with the help of data cables. This enables the use of PLC's more extensively.

As PLC's are programmable, they are programmed by desktop with the help of ethernet or other. PLC controllers are hardware devices which control the machines with the help of their logic.

PLC can be programmed by different logics as stated:

$\Rightarrow$ Ladder logic

$\Rightarrow$ Functional Block diagram

$\Rightarrow$ Sequential function chart

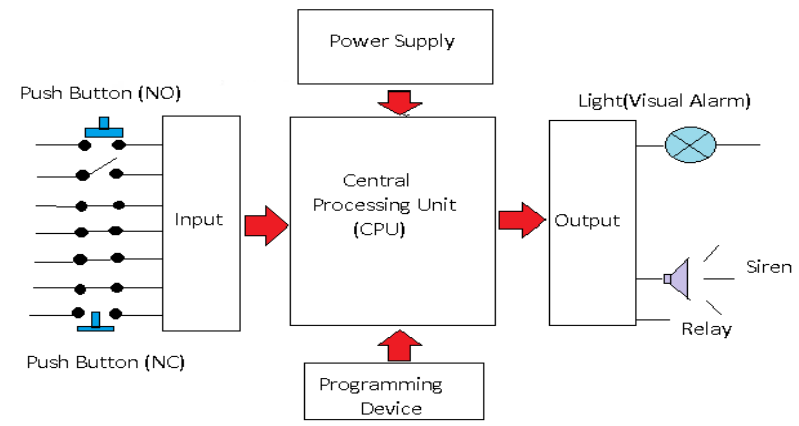

Block diagram of a PLC

\section{INDUSTRIAL AUTOMATION MARKET}

Many countries nowadays are investing to develop new methods for automation. Innovation is very beneficial in industrial automation. Robotics had developed a new trend in the industrial automation.

Internet of things or (IOT) is the major component with respect to the industrial automation, therefore industries adopting IOT has increased the demand of automation.

Automation market is growing rapidly over $6 \%$ of CAGR and is expected to reach $\$ 149$ billion (USD) by 2022.

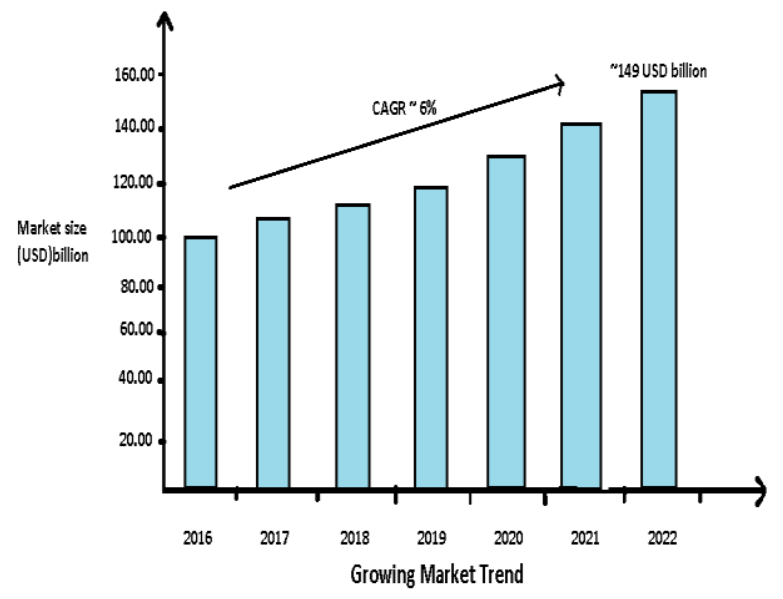

\section{ADVANTAGES}

1. With the help of automation, the task which are difficult and can't be completed by human, can be easily done[7].

2. Automatic machines are helpful at those places where human involvement is dangerous (like,fire, volcanoes, space, nuclear sites, underwater etc.)

3. It reduces manpower and labor cost.

4. Work can be done accurately and the finished products are of higher precision.

5. Reduces the work time significantly.

6. Complex jobs can be done easily and within significant time.

7. Automation helps to reduce the shortage of labor in many advanced nations.

\section{DISADVANTAGES}

1. Due to automation, the labors are replaced by heavy machines, as a result of which unemployment is increased.

2. Initial cost of automating the industry is very high and requires higher maintenance. 
3. Current technology is unable to automate all types of tasks.

\section{LIMITATIONS}

There are many jobs which requires human for their completion and can not be done by automated machines or robots. The job of a Writer can not be automated and so of a journalist and many more are in this line. Some specific jobs requires human as their basic need [8]. Also some jobs cannot be automated because initial cost of automation is high and so automation for such types of job isn't convenient neither profitable. Thus there are certain limitations to the automation of work.

\section{CONCLUSION}

After all the discussion done throughout the paper we can conclude that the basic need of the industrial automation are-:

1- To decrease regular maintenance and checkup, as softwares are used to control the machines.

2- To increase the rate of production and decrease the value of product so that it can be affordable to everyone.

3- To increase the flexibility and made the job easier.

\section{ACKNOWLEDGEMENT}

We would like to express our special thanks of gratefulness to Dr. D.S. Bankar, Head, Department of electrical engineering for their guidance and support for completing my research paper. I would also like to thank the faculty members of the department of electrical engineering who helped us with extended support.

\section{REFERENCES}

[1]. Blake, I.F., Kolesnikov,( 2006), V. Conditional Encrypted Mapping and

Comparing Encrypted Numbers. In: Di Crescenzo, G., Rubin, A. (eds.)FC. Springer, Heidelberg ,LNCS, vol. 4107, pp. 206-220.

[2]. Patnode A. M., (2006) "Simulation and Performance Evaluation of Parabolic Trough Solar Power Plants." Dept. Mech. Eng., Univ. Wisconsin, Madison,.
[3]. McDermott, D.V.: A Temporal Logic for Reasoning About Processes and Plans. Coanitive Science.

[4]. Allen, J.F.: (1983) Maintaining about Temporal Intervals. Comm. of the ACM, Val $26 \mathrm{Nr} 11$.

[5]. Maaazine A.I, (1988) Spring, pp 27 - 45. Lauber, R.J: Forecasting Real-Time Behaviour During Software Design using an ASE Environ-Int. Conf. on System Science 1989, pp 645-653.

[6]. Seaborg D.E, Edgar T.F, Mellichamp D.A., (1989) "process dynamic and Controls"wiley,.

[7]. Warnock G., (1988),Programmable controllers: Operation \& Application, prentice Hall.

[8]. Wagner .M, (2006) "Simulation and Predictive Performance Modeling of Utility-Scale Central Receiver System Power Plants," Dept. Mech. Eng., Univ. Wisconsin, Madison,

[10]. Grigg C. (1999)., "The IEEE reliability test system-1996. A report prepared by the reliability test system task force of the application of probability methods subcommittee,"," IEEE Trans. Power Syst., vol. 14, no.3, pp. 1010-1020, Aug 1999.

[11]. Agrawal D., Abbadi A. El, F. Emekci and Metwally A., (2009), Database Management as a Service: Challenges and Opportunities, Proceedings of The 2009 25th International Conference on Data Engineering, IEEE , pp. 1709-1716.

[12] D.H. (2013), “The 'Task Approach' to Labor Markets: An Overview.”, Journal for Labour Market Research, Vol. 46 No. 3, pp. 185-199.

[13] Arntz, M., Gregory, T. and Zierahn, U. (2016), "The Risk of Automation for Jobs in OECD Countries", OECD Social, Employment and Migration Working. Papers, No. 189, OECD Publishing, Paris. 